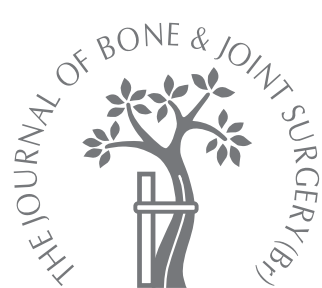

R. Civinini, M. D’Arienzo, M. Innocenti

From the Second Orthopaedic Clinic, University of Florence, Florence, Italy

R. Civinini, MD, PhD,

Orthopaedic Surgeon

= M. D'Arienzo, MD, Professor of Orthopaedic Surgery

M. Innocenti, MD, Professor

of Orthopaedic Surgery

II Orthopaedic Clinic

University of Florence, СTO -

Largo Palagi 1, 50139 Firenze,

Italy.

Correspondence should be sent to Dr R. Civinini; e-mail: civ@mclink.it

(C)2008 British Editorial Society of Bone and Joint Surgery doi:10.1302/0301-620X.90B5. $20116 \$ 2.00$

$J$ Bone Joint Surg $[B r]$ 2008:90-B:570-3.

Received 21 August 2007;

Accepted after revision 9

January 2008

\title{
A ten-year follow-up of the Reflection cementless acetabular component
}

\begin{abstract}
We reviewed the long-term results at ten to 12 years of 118 total hip replacements in 109 patients using a second-generation hemispherical cementless acetabular component (Reflection) designed to address the problem of backside wear. Five patients (five hips) died and six patients (seven hips) were lost to follow-up. The remaining 98 patients (106 hips) had a mean age of 62.9 years (34.0 to 86.2) A rate of revision for aseptic loosening of $0.9 \%$, and predictable results were found with respect to radiological evidence of fixation, lack of pain, walking ability, range of movement and function. One component was revised for aseptic loosening, and of the 101 hips $(95.2 \%)$ that did not have a revision, minor osteolytic lesions of the pelvis were seen in six (5.9\%). Kaplan-Meier survival analysis for the total cohort of 118 hips revealed a $\mathbf{9 6 . 4 \%}$ survival at both ten (95\% confidence interval 90 to 98 ) and 12 years ( $95 \%$ confidence interval 86 to 98$)$.
\end{abstract}

Modular metal-backed cementless acetabular components are widely used. ${ }^{1,2}$ Modular components give surgeons the flexibility to change the size of the femoral head and the offset and cover of the liner. They also offer the possibility of enhancing the initial bone fixation with screws. During a revision procedure the liner may be changed without removing a well-fixed shell.

When analysing the results of the first generation of cementless acetabular components, although there were low rates of loosening, there were high rates of wear and osteolysis. ${ }^{3-8}$

Wear between the femoral head and polyethylene has been recognised for many years. More recently, retrieval and in vitro studies have demonstrated that with modular components, wear between the metal shell and the polyethylene liner, so-called backside wear, also occurs and may be of clinical significance. ${ }^{9-11}$ This was observed in first-generation modular acetabular components in which there was a poor locking mechanism, allowing micromovement of the polyethylene liner, poor conformity between the liner and the shell, and a rough inner surface finish. These observations led to a number of changes in their design. ${ }^{12-14}$

The purpose of this study was to analyse the long-term results of a second-generation hemispherical cementless acetabular component (Reflection, Smith \& Nephew, Memphis, Tennessee) designed to address the problem of backside wear, with thicker polyethylene, increased conformity of the component and liner, an increase in surface area to support the liner, a polished inner metal-backing and a stable locking mechanism.

\section{Patients and Methods}

Between June 1993 and November 1996, 118 primary total hip replacements (THRs) were carried out in 109 patients using a Reflection porous-coated cementless acetabular component. Data were collected prospectively on all patients for a minimum of ten years, or until death or failure of the device. All the operations were performed at the same institution by the three authors.

During the period of follow-up five patients (five hips) died at a mean of 5.1 years ( 2 to 8 ) after operation from causes that were not related to the THR. None had required a further operation and all had satisfactory fixation of the acetabular component, as seen on radiographs made within one year of death. Six patients (seven hips) were lost to follow-up at a mean of 6.2 years (2 to 11) after the operation. These patients had no radiological evidence of loosening at the time of the last follow-up.

The remaining 106 hips (98 patients) were available for review at a mean follow-up of 12.1 years (10.0 to 13.7$)$.

These 98 patients comprised 61 women and 37 men. Their mean age at the time of operation was 62.9 years (34.0 to 86.2). Their mean weight was $71 \mathrm{~kg}$ (48 to 107). The primary 
diagnosis was osteoarthritis in 55 hips $(51.9 \%)$, osteoarthritis secondary to developmental dysplasia in 22 $(20.8 \%)$, osteonecrosis in ten $(9.4 \%)$, rheumatoid arthritis in seven $(6.6 \%)$, fracture of the femoral neck in six $(5.7 \%)$, post-traumatic arthritis in five $(4.7 \%)$, and ankylosing spondylitis in one $(0.9 \%)$.

The Reflection component is a second-generation hemispherical, titanium-alloy cementless acetabular shell with a titanium porous-coated outer surface and a smooth inner surface. At the time of surgery the system was available in two configurations, Reflections I and V. The Reflection I had a threaded hole at the apex for insertion of the component and visualisation of the acetabulum, with no additional options for fixation. The Reflection $\mathrm{V}$ had five screw/peg holes. A cover could be threaded into the apex hole of the shell in both Reflection I and V.

A direct lateral approach was used in all the cases, with the patients in a supine decubitus position. All the components were implanted with a press-fit technique. The acetabulum was reamed progressively to obtain circumferential contact with bleeding cancellous or subchondral bone. The final reamer size was determined by complete contact between the reamer and the acetabular rim, and a trial shell was then inserted. The acetabulum was under-reamed by $1 \mathrm{~mm}$ to $3 \mathrm{~mm}$.

During the first period of the study the component without a hole was not available. A component with five cluster holes (Reflection V) but with no screws was used in 50 hips $(47.2 \%)$, a component without holes (Reflection I) in 41 $(38.7 \%)$, and a component with holes and one or more screws in $15(14.1 \%)$.

The desired position of the component was $45^{\circ}$ of abduction and $10^{\circ}$ of anteversion. In all cases a $20^{\circ}$ elevated polyethylene liner was used. All the liners were made of GUR 1050 calcium stearate-free resin, machined from an extruded bar (Hoechst Celanese, Houston, Texas).

A cobalt-chromium femoral head was used in 85 hips $(80.2 \%)$ and a zirconium head in $21(19.8 \%)$, all with a diameter of $28 \mathrm{~mm}$. A cemented Spectron femoral stem (Smith \& Nephew) was used in 45 hips (42.4\%), a Charnley Elite cemented femoral stem (DePuy, Warsaw, Indiana) in 37 (34.9\%), and a Richards Modular Hip System cementless modular stem (Smith \& Nephew) in 24 $(22.6 \%)$.

The Harris hip score (HHS) was determined before operation and at the most recent follow-up. Anteroposterior and lateral radiographs were taken on these occasions. Components without radiolucent lines or evidence of migration on the radiographs taken at the last followup were considered to be well fixed. Those with a circumferential radiolucent line $<1 \mathrm{~mm}$ in width and without migration were considered to have a stable fibrous union. Those with progressive radiolucent lines or exhibiting migration were considered to be loose. The acetabular component was considered to have migrated if there was a change of $\geq 3 \mathrm{~mm}$ in the horizontal or vertical position of the centre of the component compared with the position immediately after operation. ${ }^{15}$

The prevalence, location and extent of osteolytic lesions, progressive radiolucent lines and resorptions at the calcar were determined on anteroposterior and lateral radiographs made at the last follow-up. Osteolysis was defined as a punched-out area, devoid of trabecular bone and usually with a sclerotic border. Peri-acetabular osteolytic lesions were assessed according to the zones described by DeLee and Charnley, ${ }^{16}$ and the area of each lesion was measured on the last post-operative radiograph. Resorption of the calcar, defined as rounding of the calcar with a convex shape and loss of calcar-collar contact, was differentiated from osteolysis, a punched-out, expansive area with a concave shape.

A Kaplan-Meier survival analysis was performed to calculate the survival curve of this acetabular component. Two distinct endpoints were chosen: revision, or an indication for revision for aseptic loosening or migration of the component as one, and the presence of radiologically detectable osteolysis as the other.

Survival tables were constructed using 12-month intervals. For each interval, the total number of hip replacements entering the interval, the number of failures and withdrawals, the number at risk, the annual rates of failure and success, and the cumulative success rate were calculated. Confidence intervals were calculated using the Rothman formula. ${ }^{17}$

\section{Results}

Of the 106 acetabular components, five (4.7\%) were revised. One was revised for aseptic loosening (0.9\%) after three years and required a bone graft for a protrusio deformity secondary to rheumatoid arthritis. Four hips $(3.8 \%)$ had revision of a stable acetabular component. In one the component was revised after a fourth dislocation. In the other three it was exchanged because of excessive wear. We did not perform an isolated exchange of the liner in these three cases because we were not confident about the locking mechanism.

Nine additional hips $(8.5 \%)$ were revised for aseptic loosening of the femoral stem. The acetabular component was well fixed in all these cases, and in two the liner was exchanged for a new one made from a highly cross-linked polyethylene.

The clinical and radiological results were available for the 101 hips (95.2\%) that had not undergone revision of the acetabular components.

The mean HHS improved from 43 (17 to 58) before operation to 91 (58 to 100) at the latest follow-up. The results were rated as excellent in 69 hips $(68.3 \%)$, good in $25(24.8 \%)$, fair in five $(5.0 \%)$ and poor in two $(1.9 \%)$.

The radiological results showed that 98 hips $(97.0 \%)$ had a well-fixed component with bone ingrowth at the time of the last follow-up. Three $(3.0 \%)$ had a stable fibrous 
10010099.199 .199 .199 .198 .297 .396 .496 .496 .496 .4

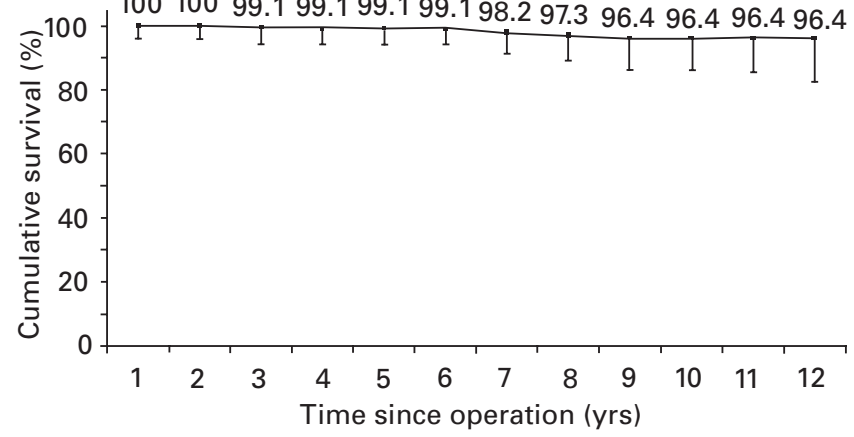

Fig. 1

Kaplan-Meier curve showing survival of the implant during a 12-year period of follow-up. The results are given as percentages with the lower limit of the $95 \%$ confidence intervals.

union, without migration of the component or associated symptoms; one, as noted above, was revised because of aseptic loosening. Radiolucent lines were present in nine $(8.9 \%)$ components in one or more zones. They were not progressive and were $<1 \mathrm{~mm}$ in width. None of these components was considered to be unstable. The group of patients with radiolucent lines was asymptomatic and their mean HHS score was 93 (82 to 100).

Osteolytic lesions were present in six cases $(5.9 \%)$. Their mean size at the last follow-up was $314 \mathrm{~mm}^{2}$ (180 to 1026). Osteolysis was noted in association with three of $40 \mathrm{com}$ ponents without holes and in three of 61 components with cluster holes. For the entire cohort of 118 hips, KaplanMeier survival analysis, with failure defined as revision or indication for revision for any reason, indicated that the Reflection component had a $96.4 \%$ survival at both ten (95\% confidence interval (CI) 90 to 98 ) and 12 years $(95 \%$ CI 86 to 98) (Fig. 1).

For a follow-up of 12 years, the probability of survival with the endpoint defined as the presence of osteolysis was 94.6\% (95\% CI 84 to 98 ).

\section{Discussion}

The success of the hemispherical acetabular component in terms of fixation is well established, and once initial stability is achieved this usually leads to long-term biological fixation. Failures have been reported to occur from the generation of polyethylene wear with resultant osteolysis, rather than by loosening. ${ }^{3,4,7}$ As the concave articular surface was the obvious source of wear, most studies focused on the generation of debris from this site. However, it later became evident that the wear on the convex surface was substantial, with the production of polyethylene particles on the non-articulating side of the polyethylene in contact with the metallic shell, termed backside wear. ${ }^{18-21}$

This wear was classified by Schmalzried and Callaghan ${ }^{22}$ as mode-4 wear, where two secondary surfaces are rubbing together. Particles produced by mode- 4 wear can induce an inflammatory reaction, and can also be transported to the bearing surfaces and induce thirdbody wear.

Osteolysis due to backside wear was seen mostly in first-generation modular acetabular components. Clinical and in vitro wear studies have associated backside wear with factors in design, including a suboptimal locking mechanism that allowed liner-shell micromovement, ${ }^{9,20}$ lack of conformity between the liner and the shell, roughness of the inner surface of the shell, ${ }^{11}$ thinner polyethylene and the presence of screw holes. ${ }^{10,14}$ Modern modular components have improved locking mechanisms, ${ }^{12,13}$ maximal conformity of the shell and liner, smooth inner metallic surfaces ${ }^{14}$ and no holes. These modifications have reduced micromovement between the shell and liner and backside wear in vitro. ${ }^{23,24}$ However, there are few published reviews analysing the results of second-generation modular acetabular components.

Della Valle et $\mathrm{al}^{25}$ described their results with a secondgeneration cementless modular acetabular component for primary THR. They found a low rate of revision for aseptic loosening $(0.3 \%)$ and of peri-prosthetic osteolysis $(5 \%)$ at a medium-term follow-up. They also compared a second-generation modular component with a nonmodular component in which the polyethylene liner was pre-assembled at the factory. They observed no movement between the liner and the shell. After a mean follow-up of 5.65 years there was no difference in the rate of wear and the prevalence of peri-prosthetic osteolysis between the two groups. ${ }^{26}$

Chen et $\mathrm{al}^{27}$ noted that changes in design made to address problems with the first-generation components resulted in no loose components or radiological evidence of migration, compared with a rate of failure of $21 \%$ of first-generation components.

In our series of 106 Reflection porous-coated acetabular components followed for a mean of 12.1 years there was a low rate of revision for aseptic loosening (0.9\%), and predictable results with respect to radiological evidence of fixation, lack of pain, walking ability, range of movement and function. We are aware that plain radiographs tend to underestimate the incidence and extent of peri-acetabular osteolysis compared with computed tomography; ${ }^{28}$ however, conventional radiographs remain the clinical standard for routine follow-up.

The Reflection acetabular component demonstrated low rates of loosening and osteolysis and no liner dissociation at a minimum of ten years after the operation. The observed rate of radiological loosening and osteolysis was less than that reported for first-generation acetabular components inserted without cement in other studies that had a similar length of follow-up. , $, 5,29-32^{-1}$

\footnotetext{
The authors are grateful to J. Bruhwyler, PhD (Squarepoint-Pointcarré) for help in preparing this manuscript.

No benefits in any form have been received or will be received from a commercial party related directly or indirectly to the subject of this article.
} 


\section{References}

1. Chmell MJ, Rispler D, Poss R. The impact of modularity in total hip arthro plasty. Clin Orthop 1995;319:77-84.

2. Harris WH. Results of uncemented cups: a critical appraisal at 15 years. Clin Orthop 2003;417:121-5.

3. Hernandez JR, Keating EM, Faris PM, Meding JB, Ritter MA. Polyethylene wear in uncemented acetabular components. J Bone Joint Surg [Br] 1994;76 B:263-6

4. Bono JV, Sanford L, Toussaint JT. Severe polyethylene wear in total hip arthroplasty: observations from retrieved AML PLUS hip implants with an ACS polyethylene liner. J Arthroplasty 1994;9:119-25.

5. Claus AM, Sychterz CJ, Hopper RH Jr, Engh CA. Pattern of osteolysis around two different cementless metal-backed cups: retrospective, radiographic analysis at minimum 10-year follow-up. J Arthroplasty 2001;16:177-82.

6. Dowd JE, Sychterz CJ, Young AM, Engh CA. Characterization of long-term femoral-head-penetration rates: association with and prediction of osteolysis. J Bone Joint Surg [Am]2000;82-A:1102-7.

7. Crowther JD, Lachiewicz PF. Survival and polyethylene wear of porous-coated acetabular components in patients less than fifty years old: results at nine to fourteen years. J Bone Joint Surg [Am] 2002;84-A:729-35.

8. Soto MO, Rodriguez JA, Ranawat CS. Clinical and radiographic evaluation of the Harris-Galante cup: incidence of wear and osteolysis at 7 to 9 years followup. $J$ Arthroplasty 2000;15:139-45.

9. Huk OL, Bansal M, Betts F, et al. Polyethylene and metal debris generated by nonarticulating surfaces of modular acetabular components. J Bone Joint Surg $[\mathrm{Br}]$ 1994;76-B:568-74.

10. Lieberman JR, Kay RM, Hamlet WP, Park SH, Kabo JM. Wear of the polyethylene liner-metallic shell interface in modular acetabular components: an in vitro analysis. J Arthroplasty 1996;11:602-8.

11. Shepard MF, Lieberman JR, Kabo JM. Ultra-high-molecular weight polyethylene wear: an in vitro comparison of acetabular metal types and polished surfaces. $J$ Arthroplasty 1999;14:860-6.

12. Kurtz SM, Ochoa JA, White CV, Srivastav S, Cournoyer J. Backside nonconformity and locking restraints affect liner/shell load transfer mechanisms and relative motion in modular acetabular components for total hip replacement. $J$ Biomech 1998;31:431-7

13. Tradonsky S, Postak PD, Froimson Al, Greenwald AS. A comparison of the disassociation strength of modular acetabular components. Clin Orthop 1993;296:15460.

14. Kurtz SM, Ochoa JA, Hovey CB, White CV. Simulation of initial frontside and backside wear rates in a modular acetabular component with multiple screw holes. J Biomech 1999;32:967-76.

15. Massin P, Schmidt L, Engh CA. Evaluation of cementless acetabular component migration: an experimental study. J Arthroplasty 1989;4:245-51.
16. DeLee JG, Charnley J. Radiological demarcation of cemented sockets in total hip replacement. Clin Orthop 1976;121:20-32.

17. Murray DW, Carr AJ, Bulstrode C. Survival analysis of joint replacements. J Bone Joint Surg [Br] 1993;75-B:697-704.

18. Bobyn JD, Tanzer M, Krygier JJ, Dujovne AR, Brooks CE. Concerns with modularity in total hip arthroplasty. Clin Orthop 1994;298:27-36.

19. Fehring TK, Smith SE, Braun ER, et al. Motion at the modular acetabular shell and liner interface: a comparative study. Clin Orthop 1999;367:306-14.

20. Chen PC, Mead EH, Pinto JG, Colwell CW Jr. Polyethylene wear debris in modular acetabular prostheses. Clin Orthop 1995;317:44-56.

21. Wasielewski RC, Jacobs JJ, Arthurs B, Rubash HE. The acetabular insert-metal backing interface: an additional source of polyethylene wear debris. J Arthroplasty 2005;20:914-22.

22. Schmalzried TP, Callaghan JJ. Wear in total hip and knee replacements. J Bone Joint Surg [Am] 1999;81-A:115-36.

23. Williams VG 2nd, Whiteside LA, White SE, McCarthy DS. Fixation of ultrahighmolecular-weight polyethylene liners to metal-backed acetabular cups. J Arthroplasty 1997:12:25-31.

24. Della Valle AG, Rana A, Furman B, Sculco TP, Salvati EA. Backside wear is low in retrieved modern, modular, and nonmodular acetabular liners. Clin Orthop 2005;440:184-91

25. Della Valle AG, Zoppi A, Peterson MGE, Salvati EA. Clinical and radiographic results associated with a modern, cementless modular cup design in total hip arthroplasty. J Bone Joint Surg [Am] 2004;86-A:1998-2003.

26. Della Valle AG, Su E, Zoppi A, Sculco TP, Salvati EA. Wear and periprosthetic osteolysis in a match-paired study of modular and nonmodular uncemented acetabular cups. J Arthroplasty 2004:19:972-7.

27. Chen CJ, Zenos JS, McAuley JP, Young A, Engh CA Sr. Second-generation porous-coated cementless total hip arthroplasties have high survival. Clin Orthop 2006:451:121-7.

28. Kitamura N, Pappedemos PC, Duffy PR 3rd, et al. The value of anteroposterior pelvic radiographs for evaluating pelvic osteolysis. Clin Orthop 2006;453:239-45.

29. Tompkins GS, Jacobs JJ, Kull LR, Rosenberg AG, Galante J0. Primary total hip arthroplasty with a porous-coated acetabular component: seven-to-ten-year results. J Bone Joint Surg [Am] 1997;79-A:169-76.

30. Clohisy JC, Harris WH. Primary hybrid total hip replacement, performed with insertion of the acetabur component without cement and a precoat femoral component with cement: an average ten-year follow-up study. J Bone Joint Surg [Am] 1999:81A:247-55.

31. Udomkiat P, Dorr LD, Wan Z. Cementless hemispheric porous-coated sockets implanted with press-fit technique without screws: average ten-year follow-up. $J$ Bone Joint Surg [Am] 2002;84-A:1195-200.

32. Gaffey ال Callaghan J J Jedersen DR, et al. Cementless acetabular fixation at fifteen years: a comparison with the same surgeon's results following acetabular fixation with cement. J Bone Joint Surg [Am]2004;86-A:257-61. 